\title{
P007. Inhibition of monoacylglycerol lipase activity modulates the activation of brain structures relevant for migraine pathogenesis
}

\author{
Rosaria Greco', Tiziano Bandiera², Antonina S Mangione ${ }^{1}$, Chiara Demartini', Giuseppe Nappi ', Giorgio Sandrini ${ }^{1}$, \\ Daniele Piomelli ${ }^{2}$, Cristina Tassorelli ${ }^{1,3^{*}}$
}

From Abstracts from the 1st Joint ANIRCEF-SISC Congress

Rome, Italy. 29-31 October 2015

\section{Background}

Experimental evidence shows that the anti-nociceptive action of endocannabinoids, related to the modulation of the trigeminovascular system activity, may be helpful for prompting new targets for the treatment of migraine. URB602 is an inhibitor of monoacylglycerol lipase (MAGL), a key enzyme in the hydrolysis of the endocannabinoid 2-arachidonoylglycerol (2-AG). URB602 induces analgesia in animal pain models not related to migraine, but there is no pre-clinical information as regards to its potential effect in migraine pain.

\section{Aim}

To evaluate whether URB602 administration interferes with the level of activation of brain structures involved in migraine.

\footnotetext{
Methods

Nitroglycerin (NTG) induces neuronal activation in a specific subset of brain nuclei that are considered relevant for the development of migraine attacks. In this study we evaluated the changes caused by URB602 in NTG-induced neuronal activation. Male Sprague Dawley rats were treated with NTG $(10 \mathrm{mg} / \mathrm{kg}$, i.p.) followed by URB602 (2mg/kg, i.p.) or vehicle (DMSO, $1 \mathrm{ml} / \mathrm{kg}$, i.p.). Their brains were processed for the detection of c-Fos protein, used as an indicator of brain activation.
}

\footnotetext{
* Correspondence: cristina.tassorelli@mondino.it

'Laboratory of Neurophysiology of Integrative Autonomic Systems, Headache Science Centre, "C. Mondino" National Neurological Institute, Pavia, Italy

Full list of author information is available at the end of the article
}

\section{Results}

URB602 alone did not change Fos expression in the brain nuclei under evaluation. When administered 3 hours after NTG, URB602 reduced NTG-induced Fos expression in all the cerebral areas that were examined, with a significant effect in nucleus trigeminalis caudalis and ventrolateral column of periaqueductal grey.

\section{Conclusions}

The inhibition of MAGL activity, with the theoretical increase of central content of 2-AG, may modulate the activation of structures involved in pain perception and pain integration in an animal model specific for migraine.

\section{Competing interests}

The authors declare to have no competing interests.

\section{Acknowledgements}

This study was supported by a grant from the Italian Ministry of Health to "C. Mondino" National Neurological Institute (Ricerca Corrente 2013).

\section{Authors' details}

'Laboratory of Neurophysiology of Integrative Autonomic Systems, Headache Science Centre, "C. Mondino" National Neurological Institute, Pavia, Italy. ${ }^{2}$ Drug Discovery and Development Department, Fondazione Istituto Italiano di Tecnologia, Genova, Italy. ${ }^{3}$ Department of Brain and Behavioural Sciences, University of Pavia, Pavia, Italy.

Published: 28 September 2015

doi:10.1186/1129-2377-16-S1-A165

Cite this article as: Greco et al:: P007. Inhibition of monoacylglycerol lipase activity modulates the activation of brain structures relevant for migraine pathogenesis. The Journal of Headache and Pain 2015 16(Suppl 1):A165. creativecommons.org/licenses/by/4.0), which permits unrestricted use, distribution, and reproduction in any medium, provided the original work is properly cited. The Creative Commons Public Domain Dedication waiver (http://creativecommons.org/publicdomain/ zero/1.0/) applies to the data made available in this article, unless otherwise stated. 